\title{
Higher Food Prices in Sub-Saharan Africa: Poverty Impact and Policy Responses
}

\section{Quentin Wodon • Hassan Zaman}

The spike in global food prices in 2008 led to significantly higher food prices across the developing world. Global commodity prices have since fallen but remain volatile, and local food prices remain high in many countries. The authors review the evidence on the potential impact of higher food prices on poverty, focusing on Sub-Saharan Africa, and examine the extent to which policy responses are able to protect the poor. They show that rising food prices are likely to lead to higher poverty in Sub-Saharan Africa as the negative impact on net consumers outweighs the benefits to producers. A recent survey shows that the most common policy response in Sub-Saharan African countries in 2008 was reducing taxes on food, while outside the region subsidies were the most popular measure. Sub-Saharan African countries also have a higher prevalence of foodbased safety net programs, some of which were scaled up to respond to rising prices. The review suggests that the benefits from reducing import tariffs on staples are likely to accrue largely to the nonpoor. Safety net programs can be more effective, but geographic targeting and other investments to strengthen safety nets are necessary to ensure that fewer people are affected by future crises. JEL codes: I32, D1, Q12

Global staple food prices rose sharply in 2007/08 relative to earlier trends, reaching a peak in mid-2008. The World Bank foodgrain price index increased from 180 to 334 between June, 2007 and June, 2008. Global wheat prices doubled in the year leading up to April, 2008, and rice prices increased from around \$370 a ton to over $\$ 1000$ a ton (Thai export) between January and April, 2008. There are differing views on the relative importance of the main factors which drove prices up. However, there is a general consensus that a combination of policy decisions (export bans by key wheat and rice producers and the use of foodgrains 
to produce biofuels) and global market trends (higher energy prices, a depreciating dollar, and increased foodgrain demand) were the main causes (Dewbre and others 2008; Heady and Fan 2008).

Rising world prices have different pass-through effects on domestic prices depending on the extent of protection, subsidies, the relative shares of domestic consumption met by imports, and domestic market structures. While these passthrough effects vary considerably, it is clear that rapidly increasing global commodity prices in 2007/08 led to higher domestic food prices and contributed to social unrest across all continents (examples include Uzbekistan, Mexico, Pakistan, and Cameroon). During the first quarter of 2008 alone there was an 80 percent increase in rice prices in Thailand, a 25 percent increase in the Philippines, a 20 percent increase in Burkina Faso, a 41 percent increase in maize prices in Kenya, and an 18 percent increase in wheat prices in Argentina. These price increases were accommodated by monetary policy and wage-price spirals which in turn triggered significant increases in food price inflation in 2007/08 ranging from the Kyrgyz Republic (32 percent) to Vietnam (26 percent) and Chile (16 percent).

Global prices have since fallen but remain high compared with earlier years. For instance the World Bank foodgrain price index in April, 2009 is still almost twice that of the five-year average leading up to June, 2007. This index fell by 40 percent between June and December, 2008 but has since risen another 13 percent between January and April, 2009, illustrating the volatility of global commodity prices. Domestic food prices have also eased in several countries-for instance the price of coarse rice in Bangladesh in March, 2009 is almost half that of a year earlier. However, for a number of reasons such as domestic food market conditions, regional supply routes, conflict, and other factors, domestic prices remain high in many other countries and in some are rising once again. For instance the average price of maize rose by 20 percent and 16 percent respectively in Honduras and Kenya in the first quarter of 2009 relative to the last quarter of 2008; during the same time period the average price of rice in the Philippines rose by 13 percent. In 11 of the 32 countries tracked by the World Food Programme, domestic food prices of key staples rose during this same period (WFP 2009).

The spike in domestic food prices in 2008 could have long-term negative effects, even in countries where this was temporary. There are clear links between higher prices, lower caloric intake, lower quality diet, and an increase in child malnutrition (Alderman, Hoddinott, and Kinsey 2006). There is also evidence that when households are faced with large negative shocks they may sell their productive assets such as seeds and livestock, thereby jeopardizing their future earnings prospects (Fafchamps, Udry, and Czukas 1998; Jalan and Ravallion 2002). Estimates which we will review more closely in this paper suggest that the recent food price spike raised poverty across a range of countries. Beyond the immediate impact of higher food prices on the cost of the food purchased by 
households, there is evidence that higher overall inflation hurts the poor the most (Easterly and Fischer 2001).

In light of the risks of serious long-term consequences of even temporary spikes in the price of essentials, the manner and extent to which the poor are insulated matters a great deal. The policy responses which countries have used to cope with higher food prices have essentially been threefold (Zaman and others 2008). The first set of policies were "economy-wide", designed to stabilize domestic food prices: they were tax cuts, use of food stocks, subsidies, and export restrictions. The second set were social protection and human development programs for mitigating the adverse impact on the poor. These two sets of policies focused on addressing the immediate impact of the food price spike. The third set of programs and policies aimed to boost domestic food production, primarily over the medium run.

We seek to provide evidence on a few questions arising from the rise in global prices with a focus on Sub-Saharan Africa. First, to what extent were the poor in Africa affected by these price rises? Second, which of the two sets of policies designed to cushion the poor during the immediate aftermath of the food price spike were most commonly used and how do responses in Africa differ from the rest of the world? Third, to what extent are the policies implemented in Africa targeted to the poor and how can they be improved? Since evidence on the impact of medium-term measures to boost food production, following the 2008 price spike, is rather scant at this stage in Africa, we focus our discussion on the immediate responses to the rise in prices: the measures taken to stabilize food prices and scale up safety net programs. We do not broaden the scope of the paper to discuss policies aimed at dampening the impact of food price volatility on producers through government agricultural pricing policies, futures contracts, and so on.

The article is divided into two main sections-poverty impacts and policy response. In the poverty impact section we start by discussing a standard methodological approach to estimating the poverty impact of rising food prices. We then review the evidence on global impacts before focusing on recent work in several African countries. In the policy response section we begin by illustrating the way Sub-Saharan African countries responded to rising food prices compared with other countries. We then discuss the merits of possible policy responses by examining the extent to which two common responses-reducing import tariffs and food-based safety net programs-benefit the poor.

\section{Assessing the Distributional and Poverty Impact of Price Rises}

In this section we discuss the commonly used Deaton (1989) framework for examining the distributional impact of higher food prices before reviewing the impact of the 2008 food price hike globally and in Sub-Saharan Africa. 
There are different methodological approaches to estimating the impact of sudden shocks or crises on household welfare. One approach is simulation, using the latest available nationally representative household surveys. A second approach involves the use of information gathered in the midst of the shock, which may often rely on nonrepresentative samples. A third approach is ex post analysis using representative household data linking the shock to outcome variables. Given the recent nature of the food price spike we rely mainly on the first approach in this review, though we also refer to the second type, particularly to obtain insights on changes in dietary quality and other coping mechanisms.

The analysis of the distributional impact of price rises follows a simple methodology outlined by Singh, Squire, and Strauss (1986) and Deaton (1989). Deaton defines a 'net consumption ratio' as the elasticity of the cost of living with respect to changes in prices. For net producers this elasticity is negative and for net consumers it is positive. In his work in Thailand, Deaton showed that middle-class farmers benefited most from a price rise relative to either the poorest or the wealthiest rural households. These methods were subsequently applied among others by Barret and Dorosh (1996) using data from Madagascar, Budd (1993) in Côte d'Ivoire, and Klytchnikova and Diop (2006) in Bangladesh. The argument made is that the nonparametric techniques implicit in Deaton's methodology do not impose any structure on the data and hence make full use of the information available.

Deaton's framework can be summarized as follows. The change in welfare following a change in prices for a household is:

$$
d w_{i}=d p\left[\left(P R_{i}-C R_{i}\right)+\eta L_{i}\right]
$$

where $d w$ is the welfare effect expressed in percentage terms of the baseline income or consumption level of household $i$; $d p$ is the percentage change in food prices (this can be estimated for one or more food consumption items); $P R$ is the food production ratio (at the aggregate level for a household, which can be proxied by the household's agricultural sales divided by its total income or consumption, though it is also feasible to analyze this variable for various food items one by one); $C R$ is the food expenditure ratio (which at the aggregate household level is captured by the household's food consumption divided by its total income or consumption, though again this can also be examined for each specific food item separately); and $\eta$ is the wage rate elasticity with respect to food price changes (a Stolper-Samuelson effect of commodity price changes on wages) and $L$ is the labor share in total household income or consumption.

The interpretation of the above equation is straightforward. If a household is a net seller of food (in the aggregate or for any specific food item) $P R$ will be larger 
than $C R$ and the household will benefit from the price increase. By contrast, if the household is a net purchaser of food, the first term in the above equation will be negative. As to the second term, it captures the potential compensating effect of higher wages, for example for those households who have some of their members providing wage labor in food-producing farms. In the absence of good estimates of these wage elasticities (especially in Sub-Saharan Africa), researchers often compute short-term effects by not including the potential gains through wages. Following Deaton's methodology, beyond statistical point estimates of the impact of higher food prices, one may also estimate nonparametric kernel regressions by location, by net market position, by occupation, and so on.

The distinction between the short and long run impact of price rises is also important. Ravallion $(1990,2000)$ uses data from Bangladesh and India to argue that while in the short run the rural poor are adversely affected when the relative price of food rises, the impact in the long run can be neutral after adjusting for changes in wage rates. This result is due to the increased price elasticity of the wage rate to the price of foodgrains in the long run. However, the extent to which wages do in fact respond to changes in food prices has been called into question. Using time series data Rashid (2002) argues that since the mid-1980s changes in rice prices have had a negligible impact on agricultural wages in Bangladesh. Using data from a number of African countries, Christiaensen and Demery (2007) extend this analysis of second-round effects by including an additional effect of increased farm productivity arising from the increase in price of food staples. Their main conclusion is that higher food prices are likely to increase poverty, even after factoring in countervailing wage and productivity effects.

There are pros and cons of using partial versus general equilibrium models for assessing the impact of food price shocks. On the one hand, general equilibrium models allow for a more comprehensive discussion of the likely impacts of food price shocks, taking into account multiplier effects and behavioral responses over the medium term. On the other hand, they tend to rely on complex modeling assumptions, so that the results can sometimes be driven by the model specification and data availability. Most of the work carried out on the impact of the 2008 food price rise relied on partial equilibrium methods using the Deaton method, though we also refer to the few which use general equilibrium tools.

\section{Global Estimates}

Clearly an increase in food prices will have uneven impacts across countries and population groups. At the macroeconomic level, countries that are net food exporters will experience improved terms of trade, while net food importers will face increased costs in meeting domestic demand. Almost all countries in Sub-Saharan Africa are net importers of cereals, and therefore likely to be affected negatively. 
Table 1. Poverty Headcount Impacts of 2005-07 global food price increases (percentage points change)

\begin{tabular}{|c|c|c|c|c|}
\hline \multirow[b]{2}{*}{ Country } & & \multirow[b]{2}{*}{ Initial \$1/day } & \multicolumn{2}{|c|}{ Poverty change } \\
\hline & & & No wage effect & With wage effect \\
\hline Bolivia & & 23.2 & 2.0 & 1.8 \\
\hline Cambodia & & 34.1 & 1.5 & 1.3 \\
\hline Madagascar & & 61.0 & 4.7 & 3.6 \\
\hline Malawi & & 20.8 & 4.4 & 4.0 \\
\hline Nicaragua & & 45.1 & 7.8 & 7.7 \\
\hline Pakistan & & 17.0 & 4.1 & 3.4 \\
\hline Peru & & 12.5 & -0.2 & -0.3 \\
\hline Vietnam & & 17.7 & -2.0 & -2.3 \\
\hline Zambia & & 75.8 & 5.0 & 4.9 \\
\hline \multirow[t]{3}{*}{ Average } & Rural & 40.8 & 2.5 & 2.2 \\
\hline & Urban & 24.5 & 3.6 & 3.2 \\
\hline & Total & 34.1 & 3.0 & 2.7 \\
\hline
\end{tabular}

Source: Ivanic and Martin (2008).

Price rises hurt net consumers of food, and the 2008 World Development Report provides estimates on the share of households who are net sellers or buyers of staple food. The data suggest that in four out of seven surveyed countries (Bolivia, Ethiopia, Bangladesh, and Zambia) the poor are net consumers, while in three others (Cambodia, Madagascar, and Vietnam) they are net producers. Most other empirical analyses suggest that the poor, and especially the urban poor, are net consumers (for example Poulten and others 2006; Christiaensen and Demery 2007) and therefore would be hurt from an increase in food prices. Urban wage rates are also unlikely to adjust to increases in food prices, at least in the short run. Effects on the rural poor are likely to be more country specific but on average they are worse off when prices rise. This is due to the fact that the poor in rural areas are often constrained by small landholdings, input costs, and distance to markets, and hence are generally unable to produce the marketable surplus required to exceed their food expenditures.

Ivanic and Martin (2008) use household survey data for nine countries and apply the Deaton framework to estimate the poverty impact of global price changes for seven key staples between 2005 and 2007 (table 1). They also use a Computable General Equilibrium (CGE) model to simulate the increase in wages for unskilled agricultural labor that would follow from the food price increase under various assumptions. Their results show that urban households are typically hit harder than rural households, though many in rural areas are also net consumers of food and therefore adversely affected by price rises. The average 
impact of a 10 percent increase for seven key food items is to raise the poverty headcount ratio by 0.4 percentage point.

Table 1 illustrates the variations across countries-with large poverty increases in Nicaragua, Zambia, Pakistan, and Madagascar, and poverty decreases in Peru and Vietnam (where a significant number of poor households are net rice producers). ${ }^{1}$ If one were to derive global estimates of the poverty impact of rising food prices by generalizing the results from these nine countries, the results would depend significantly on assumptions of the extent to which global prices are passed through to domestic consumers. A pass-through rate of 0.66 , for example, translates into a 4.5 percentage point increase in the $\$ 1 /$ day poverty headcount ratio, or an additional 105 million people in poverty. On the other hand, if we assume the pass-through rate is only 0.33 there would be an additional 45 million poor people. Clearly, there are caveats to this analysis. Aside from the price pass-through rates which generate vastly different estimates, global estimates are based on the somewhat heroic assumption that these nine countries are representative of the world population.

Another study on the global impact of the rise in food prices uses a different methodology but reaches a similar conclusion to the Ivanic and Martin estimates. Dessus, Herrera, and De Hoyos (2008) show that the average increase in urban poverty is 4 percentage points using a CGE microsimulation model. The authors also estimate the increase in poverty depth due to the rise in prices and show that 90 percent of this increase arises from those already poor.

As is well known even temporary increases in food prices can worsen malnutrition levels, potentially leading to irreversible health and productivity impacts. Using relatively simple assumptions about the relationship between food prices and malnutrition, and the pass-through of global to local prices, an additional 44 million individuals may have become malnourished in 2008 due to the spike in food prices (World Bank 2008). Moreover the real costs of switching away from micronutrient rich food to cheaper staples may only show up in later years as immune systems weaken and morbidity rises.

\section{Estimates from Sub-Saharan Africa}

The Deaton framework was applied by Wodon and others (2008a) to more than a dozen West and Central African countries to simulate the poverty impact of a range of price increases of key imported staples. ${ }^{2}$ The authors consider only the short-term impact on poverty of higher food prices, as estimated by looking at the consumption and production of food by households, without taking wage effects into account. They present estimates using both the standard Deaton methodology, where both consumers and producers face the same price increases, as well as a variant of this where only consumers are assumed to face this price increase. 
Table 2. Poverty Headcount and Depth Impact of a 50 Percent Increase in Food Prices

\begin{tabular}{lccccccc}
\hline & \multicolumn{3}{c}{ Poverty headcount } & & \multicolumn{3}{c}{ Poverty gap } \\
\cline { 2 - 4 } \multicolumn{1}{c}{ Country } & Baseline & Upper bound & Lower bound & & Baseline & Upper bound & Lower bound \\
\hline Ghana & 28.5 & 30.4 & 29.7 & & 9.6 & 10.3 & 9.9 \\
Liberia & 63.8 & 69.8 & 69.4 & & 24.4 & 28.3 & 28.1 \\
Sierra Leone & 66.4 & 69.6 & 68.5 & & 27.5 & 29.7 & 28.7 \\
Togo & 61.6 & 63.7 & 63.6 & & 22.9 & 24.2 & 24.1 \\
DR Congo & 71.3 & 76.2 & 73.7 & & 32.2 & 32.7 & 32.5 \\
Guinea & 49.1 & 52.1 & 50.7 & & 17.2 & 18.6 & 17.6 \\
Gabon & 32.7 & 36.7 & 36.2 & & 10.0 & 11.7 & 11.5 \\
Mali & 47.5 & 52.8 & 50.9 & & 16.7 & 18.8 & 17.8 \\
Niger & 62.1 & 70.0 & 69.6 & & 25.9 & 29.6 & 29.4 \\
Nigeria & 54.7 & 57.8 & 55.7 & & 22.5 & 24.2 & 17.0 \\
\hline \multicolumn{2}{l}{ Source: Adapted from Wodon and others (2008a). } \\
\hline
\end{tabular}

Since the extent to which global prices affect local producer prices is difficult to assess, ${ }^{3}$ the authors present estimates obtained when considering only the impact on consumers as an upper bound of the impact of the rise in prices on poverty, and they interpret the results obtained when factoring in a proportional increase in incomes for net sellers as a lower bound of the impact. For comparability purposes all the simulations are based on the same price increases (25 and 50 percent) for all countries and food items (the detailed country studies consider many other intermediate price changes and are based on country-specific poverty lines). One caveat is that the price changes which are simulated are nonmarginal and hence some substitution away from the imported goods in these cases is likely, moderating some of the adverse poverty impact, though the extent of this will partly depend on the behavior of other staple prices and their availability.

With a 50 percent increase in prices the average increase in the poverty headcount is 4.4 percentage points when only the impact on the consumer side is taken into account. This falls to 2.5 percentage points when the positive impact on producer incomes is accounted for (Wodon and others 2008a). The difference across countries is due to several reasons, such as the extent that staple diets are diversified and the extent of import dependence. Table 2 provides a comparison of the upper and lower bound estimates for both the poverty headcount and poverty gap at the national level. The differences between the upper and lower bounds are smallest for Niger, Liberia, and Gabon, as these are three countries with substantial net imports of food with higher prices making a minimal impact on the domestic producer.

Wodon and others (2008a) show that most of the increase in the poverty gap shown in table 2 is due to higher poverty among households who were already 
poor. The impact on future generations is potentially serious, and a recent study, albeit using nonrepresentative samples, further illustrates this. In Monrovia, the capital of Liberia, where over 90 percent of the rice consumed is imported, there was a 40 percent increase of new admissions to a feeding program catering to severely malnourished children compared to the same period the previous year. Interviews at this site pointed to a switch to cheaper, less nutritious diets. In Sierra Leone, the price of rice increased by 64 percent between January and March, 2008. A study in a few districts found that had led to households consuming about 10 percent less rice compared to a year earlier as well as switching out of micronutrient rich foods. The poorest families reported sending fewer children to school and avoiding hospitals (ACF 2009).

Impacts vary not only between countries, but also between urban and rural areas within countries, and across regions. In many countries poverty impacts are larger in percentage points in urban areas than in rural areas, but this is not always the case. Using poverty mapping techniques, Coulombe and Wodon (2008) show that in many countries the poverty impact changes substantially from one small geographic area to another, and overall are often larger in rural municipalities than in urban ones, although the reasons for this may be different between countries. In Ghana, for example, this is essentially because poverty is low in urban areas in comparison to other countries, and only a small percentage of urban dwellers fall into poverty with the price shock. On the other hand, in Senegal, this is in part because a large share of food consumption in the country is imported, so that rural households are not protected to the same extent from the price shock through autoconsumption.

There is also some evidence of the food price impact in East and Southern Africa. Evidence from Uganda using the Deaton methodology discussed earlier, and actual changes in prices of key staples in local markets, shows that the impact on the poverty headcount and poverty gap from higher food prices is estimated at 2.6 percentage points and 2.2 percentage points respectively (Simler 2009). The analysis shows that 84 percent of the increase in poverty is due to the welfare loss of those already below the poverty line, which is consistent with global estimates showing that it is the existing poor who suffer most.

This analysis as well as that of Benson (2008) using the same nationally representative household survey shows that those for whom maize constitutes a large share of calorie intake are particularly vulnerable. Maize prices rose most (more than doubling in price in Central and Northern Uganda between October, 2007 and October, 2008) and constitute 16 percent of the average Ugandan calorie intake. However, for the urban poor maize is 26 percent of the diet and, for internally displaced people in humanitarian camps, it is 41 percent of their calorie intake. The variety of staples in the Ugandan diet could potentially have compensated for the rise in global, and local, maize prices. However, prices of 
other key staple foods also rose sharply in 2008. The price increases for cassava (161 percent), matooke ( 54 percent), and sweet potato ( 44 percent) were particularly steep in Northern Uganda, and as a result households in this area were worst affected. Moreover, since Northern Uganda had the largest concentration of the poor to start with, this increase in food prices is likely to have worsened regional inequalities.

The fact that the distributional impact of rising food prices affects poor households partly based on where they live is also clearly illustrated by recent work on Mozambique. Arndt and others (2008) using simulations based on nationally representative data show that urban households and those who live in the south of the country are adversely affected by rising food prices, while those in the north and center of the country, especially better-off farmers, typically benefited.

Prior to concluding our review of poverty impacts it is worth emphasizing two points. First, we focused our discussion on the impact on consumption poverty mirroring the focus of recent analytical work on the food price spike. Yet the impact on worsening malnutrition, school drop-outs, and adverse gender consequences of households struggling to access sufficient food is just as, if not more, important, as the early evidence from Liberia and Sierra Leone show.

Second, as has been shown, impacts differ substantially between geographical areas within a country, which poses a dilemma for policymakers. On the one hand, the desire to help households cope with the increase in food prices may lead policymakers to implement or expand safety net interventions in the hardest hit areas. On the other hand, these hard-hit areas may not necessarily be among the poorest in the country. Hence, the effectiveness of the country's overall poverty reduction strategy may be jeopardized if public resources are diverted from the poorest areas to less poor areas to address the food crisis, and trade-offs between immediate responses and medium-term measures to reduce chronic poverty may emerge.

\section{Policy Responses to Rising Food Prices in Sub-Saharan Africa}

In this section we review the results of a survey on the policy responses to the sharp rise in food prices in 2008 before examining two specific instruments-lowering foodgrain taxes and expanding food-based safety nets-in more depth.

\section{Policies in Surveyed Countries}

Countries vary widely in the type of policies or programs they are able to introduce, or scale-up, to respond to rising commodity prices. As discussed earlier there are essentially three broad types of policies that are used to respond to a 
sharp rise in food prices. The first set includes policies which attempt to stabilize rising prices by affecting the aggregate supply and demand balance. These include reducing taxes on foodgrains (import tariffs and sales taxes), using food grain stocks to increase supply, using some form of subsidy on essential items, and imposing export restrictions on staple food items.

A survey of 120 country teams carried out by the World Bank in March, 2008 shows that in Sub-Saharan Africa the most common 'economy-wide' policy response was to reduce foodgrain taxes-either tariffs, VAT, other sales tax, or a combination of these measures. On the other hand, the most common response outside Sub-Saharan Africa was some form of subsidy on essential items, which is what over half of these countries used to stabilize domestic prices (see figure 1). These subsidies have a long history in several countries and vary significantly in the extent to which they create distortions and generate fiscal pressures. For instance in Eastern Europe formal or tacit agreements between producers and the government on either actual prices or profit margins are common for basic staples. These restrictions can create producer disincentives. In the Middle East and North Africa, universal subsidies on key items are an important part of the social compact between the State and the citizens in several countries. These are known to be fiscally expensive and crowd out spending on other social programs. In South Asia, several countries have targeted subsidies on "inferior goods" (for example coarse rice in Bangladesh) which are used during crises and typically create the fewest distortions. Only 30 percent of Sub-Saharan African countries used some form of subsidy. This lower share is most likely due to the greater fiscal and administrative constraints in Africa relative to non-African countries. In some ways these constraints are a blessing in disguise for Sub-Saharan Africawidespread use of these subsidies makes them difficult to remove, reduces the

Figure 1. Economy-wide Policy Responses to Rising Food Prices

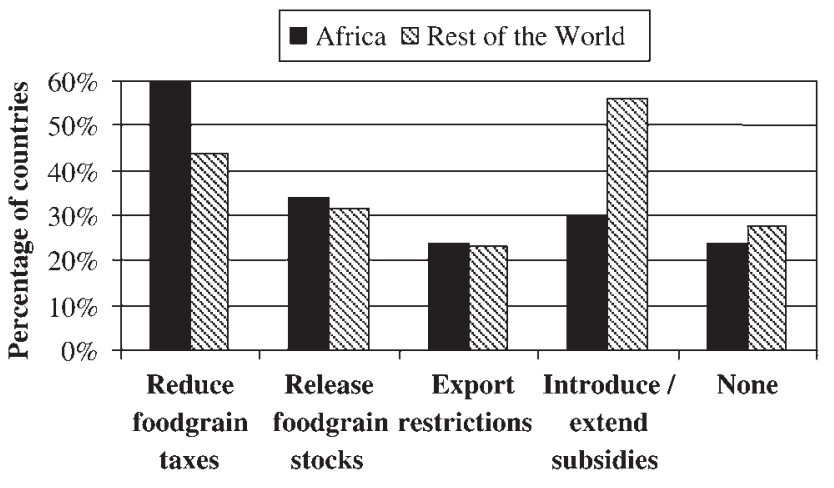


incentives for the development of alternative better targeted safety net programs, and can risk curbing an agricultural supply response.

Around a third of countries in Sub-Saharan Africa used foodgrain stocks to increase domestic supply and curb prices - this ratio is similar to the global average. The transportation, storage, and rotation of physical stocks require considerable expertise and these strategic grain reserves have had their share of corruption problems. Yet the pressures arising from the virtual suspension of rational pricing mechanisms on global foodgrain markets in early 2008, with consequent knock-on impacts in local markets, has led to a renewed interest in building up physical reserves, which can then be released during crises.

Export restrictions were as common outside Sub-Saharan Africa (23 percent of countries) as they were for countries within Africa. Governments typically introduce such measures due to pressures from the domestic political economy, though it is unclear whether these measures have any impact on domestic prices. What is clear is that when these are imposed by large grain exporting countries they have serious food security implications for neighboring countries and for regional commodity markets.

The second broad type of policy response revolves around using existing safety net instruments to either increase benefit levels or increase beneficiary coverage. However, while many countries in Sub-Saharan Africa have food-based transfer programs (figure 2), the coverage of these programs tends to be small (in part due to lack of financing), relative to needs. In Burundi, Central African Republic, Ghana, Liberia, and Togo school feeding programs were expanded, while in Guinea and Sierra Leone public works programs were set up. As Figure 2 shows from survey responses by World Bank country teams in March, 2008, some countries in Sub-Saharan Africa have cash based programs. For example, Ethiopia was able to respond by expanding the benefit levels of its major cash transfer

Figure 2. The Distribution of Safety Net Programs

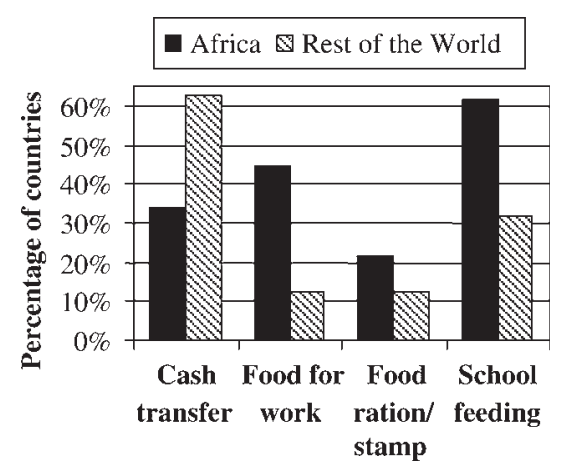


program. ${ }^{3}$ Informal networks and family based support mechanisms are an important part of the safety net, though these were strained during the food price spike. The ability to scale up safety net programs during these crises is limited by both fiscal constraints-worsened by economy-wide measures such as reducing taxes or increasing subsidies - and capacity constraints. These include weaknesses in targeting vulnerable groups as well as food and cash management issues. Yet given the range and frequency of shocks in Sub-Saharan Africa strategic choices will need to be made so that the fiscal space and requisite capacity for scaled up safety nets is created.

The third type of policy measure involves supporting domestic food production, though impacts here typically accrue over the medium term. Scaling up or introducing free or subsidized input distribution (for example Malawi), or the government import of fertilizers (for example Ethiopia and Tanzania), are common short-term responses, though they often have significant fiscal consequences. Over the medium run African countries, through the New Partnership for Africa's Development (NEPAD) mechanism, have committed to increasing their investments on agricultural research and extension as well as on irrigation and new technology.

In practice countries combined economy-wide policies and safety net programs as their immediate response to the food price hike. Country examples are illustrative of this mix. Liberia's response revolved around reducing import taxes on foodgrains and scaling up targeted feeding programs. Kenya imported 3 million metric tons of maize and subsidized fertilizer. Guinea introduced a targeted consumer subsidy for rice and expanded an existing school feeding program to urban areas. Cameroon sharply reduced VAT and customs duties on basic food staples as well as on imports of agricultural inputs while raising civil service wages. There are no studies which examine the cumulative effectiveness of these policies. We therefore limit ourselves to reviewing recent work on the extent to which the poor are likely to be targeted by two types of policy-indirect tax cuts and food-based safety nets-which are commonly used in Sub-Saharan Africa.

\section{Economy-Wide Policies: The Case of Indirect Tax Cuts}

As figure 1 illustrates almost half of the governments in Sub-Saharan Africa have reduced taxes levied on food items, such as import taxes and VATs, in order to deal with the increase in food prices. An IMF survey shows that most of these cuts were in import tariffs as they were easier to administer than VAT (IMF 2008). Wodon and others (2008b) estimate the extent to which the poor are likely to benefit from a reduction in indirect taxes. The authors provide data on the consumption of various imported foods for the same set of West and Central African countries discussed earlier. The share of rice consumption in the bottom 
40 percent of the population varies from 11 percent in Mali to 32 percent in Sierra Leone, averaging around 20 percent. This means that if one considers the bottom 40 percent as the poor, out of every dollar spent by a government for reducing indirect taxes on rice, and assuming that the indirect tax cuts results in a proportionate reduction in consumer prices, only about 20 cents will benefit the poor on average. From the consumer perspective the extent of the benefit will clearly also depend on the extent of initial tariffs and the magnitude of the tariff cut. In West Africa most import tariffs on food staples were below 15 percent. For most of the other imported foods for which indirect tax cuts were implemented, the proportions of those foods consumed by the poor tend to be even lower than that for rice. If we therefore assume that the share of imported foods represented at most 10 percent of average household consumption then the real income gain even from a complete elimination of tariffs would be no more than 1.5 percent.

Thus, while reducing taxes is a popular "stroke of the pen" measure, it suffers from several weaknesses. First, it can be costly in budgetary terms if these are permanent cuts. For instance the reduction in taxes following the rise in food prices was as much as 1.1 percent of GDP in Liberia and 0.8 percent in Senegal, and equivalent to 7 percent of tax revenues in Guinea Bissau, worsening an already tight fiscal balance. Second, for many food items, much of the benefit of the tax cuts will accrue to the nonpoor and the real income gains for the poor will be marginal. Third, compared to reducing VAT or a sales tax, lowering import tariffs may well hurt domestic producers in the short run, and in some circumstances reducing import tariffs may increase poverty. Hence the decision to reduce tariffs would need to balance the benefits for the poor in terms of the reduction in retail prices and political economy gains, with the costs outlined here.

\section{Food-Based Safety Net Programs}

As figure 2 shows food-based safety net programs are more common in SubSaharan Africa compared with other regions. In this section, we focus on the targeting performance of three types of food-based safety nets-food aid as typically distributed by humanitarian agencies, school feeding programs, and public works which often make payments in kind (but may also provide cash benefits).

Using nationally representative household survey data a recent assessment of a World Food Programme (WFP) feeding programme in Burundi shows that there was little difference in the likelihood of receiving food aid between various groups of households (Diang'a, Wodon, and Zoyem 2009). The share of total food distribution obtained by the poor was in fact slightly lower than the share of the poor in the total population. The main shortcoming appeared to be that this program did not specifically target areas in the north where food insecurity was most 
severe-which WFP now does. Clearly, using poverty maps is important for making the most out of scarce resources.

Analysis from a 2007 nationally representative household survey in Liberia shows that 22 percent of the population received some form of food aid. School feeding was the most common (74 percent were recipients of food aid), followed by food-based public works projects and nutritional supplementation. Similar to Burundi, estimates of the targeting performance of these programs suggest that nonpoor households are essentially as likely to benefit from food aid as poor households. There are differences in targeting estimates across programs (school feeding programs are slightly pro-poor, while other programs are slightly in favor of the nonpoor), but these differences are not large (Tsimpo and Wodon 2008b). Gilligan and Hoddinott (2007), using longitudinal data from Ethiopia, compare the targeting and food security outcomes of a feeding program and a Food for Work program. They find that the feeding program was better targeted to the extreme poor, while the benefits from the public works program accrued mainly to the middle and upper end of the distribution.

Del Ninno, Dorosh, and Subbarao (2007) review the experience with food aid in two East African countries (Ethiopia and Zambia) and two South Asian countries (India and Bangladesh). Their results suggest that to be effective food aid needs to be timed to avoid local producer disincentive effects and be channeled in a manner which helps create local level infrastructure-all characteristics of a well-functioning public works program. The drawback with such programs is that participants have to give up other employment in order to participate in these programs, and hence they are more suitable for shocks, or lean seasons, which create unemployment. Adato and Haddad (2002) find that among a sample of public works projects in South Africa, about 90 percent outperformed an untargeted transfer scheme. Teklu and Asefa $(1997,1999)$ find that in rural Botswana and Kenya, the poor are more likely to participate in public works programs than the nonpoor and have a substantial positive impact on their income. At the same time, a substantial number of nonpoor individuals also participate in the schemes, so that targeting performance could be improved.

Using data from Chad, Ghana, Liberia, and Rwanda Wodon and others (2008c) define the overall leakage rate in public works programs as the share of program outlays that are likely not to raise the incomes of the poor, either because program participants are not poor or because of the income foregone from alternative employment. The authors show that if public works programs are randomly placed within the country, the leakage rates are potentially high, varying from 50 percent to close to 75 percent in all four countries. On the other hand, if the programs are geographically targeted, targeting performance can improve substantially. In Ghana, for example, the simulated leakage rate for a hypothetical randomly placed public works program is very high, at 73 percent, 
while it could be as low as 18 percent if resources were only concentrated in the Upper West region of the country.

This review shows that the food-based safety net programs more commonly used in Sub-Saharan Africa can be effectively targeted to the poor with clear benefits to household welfare, but that there is considerable variation across programs and contexts. The choice of program depends on a range of factors, such as the type and duration of the shock being faced by the community, the administrative capacity, and budgetary constraints. School feeding programs may be particularly effective for retaining poor children in school following a real income shock such as a sharp increase in food prices. Public works programs may be more effective during lean seasons or following lay-offs during an economic downturn. Timing is also crucial. For instance administrative structures need to be in place to enable interventions during the lean seasons, thereby avoiding households having to consume their seeds and selling their assets. In many countries, given large differences in consumption and nutrition levels between regions, geographic targeting could be used to improve program effectiveness. Furthermore in order to address chronic food insecurity for vulnerable groups, regular fortified food provision, and other essential nutritional interventions aimed at reaching children under five and pregnant mothers, are required yearround.

\section{Conclusion}

The first objective of this article was to review the evidence regarding the potential impact of the recent increase in food prices on poverty focusing on SubSaharan African countries. The second objective was to document the policy responses adopted by governments to cushion the poor from the immediate impacts of this crisis, and to assess the extent to which the poor may have been reached by these policies. Two main findings stand out from our review.

First, due to the higher share of net consumers relative to net producers in most countries, higher food prices leads to increased poverty even when secondround wage effects are taken into account. The bulk of the welfare loss from higher prices accrues to those who are already poor, and the evidence from SubSaharan Africa shows that increases in the poverty gap can be significant. Recent analysis in Sierra Leone and Liberia, albeit using nonrepresentative samples, shows that households cut back on rice consumption and significant numbers cut back their consumption of micronutrient rich foods. The poorest families reported sending fewer children to school and avoiding hospitals. Hence even if these price increases were temporary-and it is unclear to what extent this is the casethese price shocks can have long-lasting impacts. 
Second, governments potentially have various tools at their disposal to deal with the immediate impact of the increase in food prices, with important differences in the effectiveness of these tools. The types of policies which are used to deal with crises vary considerably across continents. In Eastern Europe and the Middle East for instance there is a long history of universal subsidies and controls on producer prices. These policies clearly have significant fiscal costs and require a fairly extensive state apparatus to implement, which may partly explain why these instruments are less common in Sub-Saharan Africa. On the other hand targeted subsidies (using products typically consumed by the poorest) deployed during sudden shocks, or lean seasons, can be an effective way to protect the poor while not creating excessive fiscal costs or economic distortions. In SubSaharan Africa, almost half the countries surveyed following the increase in food prices reduced taxes on foodgrains. We argue that the bulk of the benefits from a cut in tariffs accrued to the nonpoor, and the paltry real income gains for the poor, are most likely not worth the tax revenue foregone.

In addition to economy-wide policies, governments have scaled up safety net programs in an effort to cushion the poor from the impact of higher food prices. Safety net programs tend to be better targeted than economy-wide policies, though our review suggests that they can also suffer from significant leakages to the nonpoor and face fiscal and administrative constraints. The limited evidence available on feeding and public works programs suggests that their targeting performance can be improved considerably, for instance through the use of geographic targeting. Moreover in most Sub-Saharan African countries the coverage and generosity of safety net programs falls significantly short of the size and needs of their vulnerable populations.

Hence it is clear that in practice most governments in Sub-Saharan Africa have limited instruments to address events such as the 2008 spike in food prices and yet there are strong political pressures for them to do so. Given the absence of well-targeted safety nets with adequate coverage in many countries, it could be that some of the "economy-wide" measures that were adopted by governments were necessary both for reasons of political economy as well as for practical reasons. Moreover some of these economy-wide options are less costly than others, and time-bound and targeted subsidies, for instance, may be as cost effective as any other alternative policy option to protect the poor. Yet experience from other countries shows that investments in the building blocks of safety net programs could yield tangible improvements in the lives of a large proportion of poor households at the time of the next crisis. Specifically, investments in targeting methods and data, payment systems, accountability mechanisms, and monitoring are required (see Grosh and others 2008 for more details). These can create the basis for a safety net menu which includes regular year-round programs for vulnerable groups (for example infants, pregnant women, the disabled) as well as 
temporary programs which scale up during lean seasons or during shocks. Finally, although medium to long term initiatives to boost food production have not been discussed here, these initiatives are clearly necessary as part of an overall package of policies to stimulate pro-poor growth and reduce household vulnerability to shocks.

\section{Notes}

Quentin Wodon is an adviser in the Development Dialogue on Values and Ethics in the Human Development Network. Hassan Zaman (corresponding author) is a lead economist in the Poverty Reduction Group in the Poverty Reduction and Economic Management (PREM) Network; email address: hzaman@worldbank.org. The authors benefited from discussions and comments with, among others, Douglas Addison, Harold Alderman, Antonella Bassani, Louise Cord, Shanta Devarajan, Hinh Dinh, Wilfried Engelke, Louise Fox, Delfin Go, William Martin, Ana Revenga, Sudhir Shetty, Kenneth Simler, Linda Van Gelder, and Jan Walliser. The opinions in this paper are those of the authors only, and need not represent those of the World Bank, its executive directors, or the countries they represent.

1. Ivanic and Martin also show that the effect of a relatively small 10 percent change in prices can be a first-order approximation for the impact of a larger change, though some results vary significantly depending on the extent of the clustering of households around the poverty line. In rural Peru, for instance, the impact of a 20 percent price rise on the poverty headcount is five times greater than that of a 10 percent rise.

2. For more detailed country studies, see for example Joseph and Wodon (2008) on Mali; Wodon, Tsimpo, and Coulombe (2008) on Ghana; and Tsimpo and Wodon (2008a) on Liberia.

3. Field interviews in 2008 revealed that due to the sharp erosion in purchasing power due to high inflation, the vast majority of participants in the Productive Safety Net Program would have preferred in-kind payments instead of the cash transfer (Hobson 2009).

\section{References}

The word processed describes informally reproduced works that may not be commonly available through libraries.

ACF (Action Against Hunger). 2009. "Feeding Hunger and Insecurity: The Global Food Crisis." Briefing Paper.

Adato, M., and L. Haddad. 2002. "Targeting Poverty through Community-Based Public Works Programmes: Experience from South Africa." Journal of Development Studies 38(3): 1-36.

Alderman, H., J. Hoddinott, and B. Kinsey. 2006. "Long Term Consequences of Early Childhood Malnutrition." Oxford Economic Papers 58(3): 450-74.

Arndt, C., R. Benfica, N. Maximiano, A. Nucifora, and J. Thurlow. 2008. "Higher Fuel and Food Prices: Economic Impacts and Responses for Mozambique." International Food Policy Research Institute.

Barrett, C.D., and P.A. Dorosh. 1996. "Farmers' Welfare and Changing Food Prices: Nonparametric Evidence from Rice in Madagascar.” American Journal of Agricultural Economics 78(3): 656-69. 
Benson, T. 2008. An Assessment of the Likely Impact of Rising Global Food Prices on Ugandan Households. Kampala: IFPRI.

Budd, J.W. 1993. "Changing Food Prices and Rural Welfare: A Non-Parametric Examination of the Côte d'Ivoire." Economic Development and Cultural Change 41(3): 587-603.

Christiaensen, L., and L. Demery. 2007. Down to Earth: Agriculture and Poverty Reduction in Africa. Washington, DC: World Bank.

Coulombe, H., and Q. Wodon. 2008. "Geographic Impacts of the Food Price Crisis in Sub-Saharan Africa." Processed. World Bank, Washington, DC.

Deaton, A. 1989. "Rice Prices and Income Distribution in Thailand: A Non-Parametric Analysis." The Economic Journal 99 (395): 1-37.

Del Ninno, C., P.A. Dorosh, and K. Subbarao. 2007. "Food Aid, Domestic Policy and Food Security: Contrasting Experiences from South Asia and Sub-Saharan Africa." Food Policy. 32(4): 413-35.

Dessus, S., S. Herrera, and R. De Hoyos. 2008. "The Impact of Food Inflation on Urban Poverty and its Monetary Cost: Some Back of the Envelope Calculations." Agricultural Economics 39:417-29.

Dewbre, J., C. Giner, W. Thompson, and M. Von Lampe. 2008. "High Food Commodity Prices: Will They Stay? Who Will Pay?” Agricultural Economics 39:393-403.

Diang'a, E., Q. Wodon, and J.-P. Zoyem. 2009. « L'insécurité alimentaire et l'aide alimentaire au Burundi.» Processed. World Bank, Washington DC.

Easterly, W., and S. Fischer. 2001. "Inflation and the Poor." Journal of Money, Credit and Banking 33(2): 160-78.

Fafchamps, M., C. Udry, and K. Czukas. 1998. "Drought and Saving in West Africa: Are Livestock a Buffer Stock?" Journal of Development Economics 55(2): 273-305.

Gilligan, D.O., and J. Hoddinott. 2007. "Is There Persistence in the Impact of Emergency Food Aid? Evidence on Consumption, Food Security, and Assets in Rural Ethiopia." American Journal of Agricultural Economics 89(2): 225-42.

Grosh, M., C. Del Ninno, E. Tesliuc, and A. Ouerghi. 2008. For Protection and Promotion: The Design and Implementation of Effective Safety Nets. Washington, DC: World Bank.

Heady, D., and S. Fan. 2008. "Anatomy of a Crisis: The Causes and Consequences of Surging Food Prices.” Agricultural Economics 39:375-91.

Hobson, M. 2009. "The Food Price Crisis and its Impact on the Ethiopian Productive Safety Net Programme in 2008." Humanitarian Exchange 42, Overseas Development Institute, London.

IMF (International Monetary Fund). 2008. Food and Fuel Prices—Recent Developments, Macroeconomic Impact and Policy Responses. Washington, DC: International Monetary Fund.

Ivanic, M., and W. Martin. 2008. "Implications of Higher Global Food Prices for Poverty in LowIncome Countries." Agricultural Economics 39:405-16.

Jalan, J., and M. Ravallion. 2002. "Household Income Dynamics in Rural China.” Discussion Paper 2002/10. United Nations University, World Institute for Development Economics Research.

Joseph, G., and Q. Wodon. 2008. "Assessing the Potential Impact on Poverty of Rising Cereals Prices: The Case of Mali." Policy Research Working Paper 4744. World Bank, Washington, DC.

Klytchnikova, I., and N. Diop. 2006. "Trade Reforms, Farm Productivity, and Poverty in Bangladesh.” Policy Research Working Paper 3980. World Bank, Washington, DC.

Poulton, C., J. Kyddd, S. Wiggins, and A. Dorward. 2006. "State Interventions for Food Price Stabilization in Africa: Can it Work?” Food Policy 31:342-56.

Rashid, S. 2002. "Dynamics of Agricultural Wage and Rice Price in Bangladesh: A Reexamination." Discussion Paper 44, International Food Policy Research Institute, Washington DC. 
Ravallion, M. 1990. "Welfare Changes of Food Price Changes under Induced Wage Responses: Theory and Evidence for Bangladesh." Oxford Economic Papers 42:574-85.

2000. "Prices, Wages and Poverty in Rural India: What Lessons Do the Time Series Data Hold for Policy?" Food Policy 25(3): 351-64.

Simler, K. 2009. “The Impact of Higher Food Prices on Poverty in Uganda.” Processed. World Bank, Washington DC.

Singh, I., L. Squire, and J. Strauss. 1986. Agricultural Household Models: Extensions and Applications. Baltimore: Johns Hopkins University Press.

Teklu, T., and S. Asefa. 1999. "Who Participates in Labor-Intensive Public Works in Sub-Saharan Africa? Evidence from Rural Botswana and Kenya." World Development 27(2): 431-8.

1997. "Factors Affecting Employment Choice in a Labor-Intensive Public Works Scheme in Rural Botswana." Economic Development and Cultural Change 46(1): 175-86.

Tsimpo, C., and Q. Wodon. 2008a. "Rice Prices and Poverty in Liberia." Policy Research Working Paper 4742. World Bank, Washington, DC.

2008b. "Targeting Performance and Impact of Food Aid in Post-Conflict Countries: Evidence from West and Central Africa." Processed. World Bank, Washington, DC.

WFP (World Food Programme). 2009. "Trends in Staple Food Prices in Vulnerable Countries." Issue 3 (March), Rome.

Wodon, Q., C. Tsimpo, and H. Coulombe. 2008. "Assessing the Potential Impact on Poverty of Rising Cereals Prices: The Case of Ghana." Policy Research Working Paper 4740, World Bank, Washington, DC.

Wodon, Q., C. Tsimpo, P. Backiny-Yetna, G. Joseph, F. Adoho, and H. Coulombe. 2008a. "Potential Impact of Higher Food Prices on Poverty: Summary Estimates for a Dozen West and Central African Countries.” Policy Research Working Paper 4745, World Bank, Washington, DC.

2008b. "Are Indirect Tax Cuts to Protect the Poor from Higher Food Prices Well-targeted?" Processed. World Bank, Washington, DC.

Wodon, Q., P. Backiny-Yetna, H. Coulombe, and C. Tsimpo. 2008c. "Targeting Performance of Labor Intensive Public Works in Africa: Simulations for Four Countries." Processed. World Bank, Washington, DC.

World Bank. 2008. Rising Food and Fuel Prices: Addressing the Risks to Future Generations. Washington, DC: World Bank.

Zaman, H., C. Delgado, D. Mitchell, and A. Revenga. 2008. "Rising Food Prices: Are There Right Policy Choices?" Development Outreach, Washington, DC: World Bank. 